\title{
Trabalho como mediação da comunicação: Uma reflexão teórica sobre o binômio comunicação-trabalho e os estudos de recepção
}

\author{
Lizbeth Kanyat \\ Doutoranda em Comunicação e Práticas \\ de Consumo na Escola Superior de \\ Propaganda e Marketing - ESPM. \\ Também é docente e coordenadora do \\ curso de Comunicação Social do Centro \\ Universitário Adventista de São Paulo - \\ UNASP. Obteve seu mestrado em \\ Comunicação pela ESPM (2014), com \\ estágio de pesquisa no Centro \\ Internacional de Estudios Superiores de \\ Comunicación para América Latina \\ (CIESPAL), em Quito - Equador. \\ E-mail: lizbethkanyat@gmail.com
}

Resumo: $O$ presente trabalho situa-se no binômio comunicação-trabalho, buscando refletir sobre os estudos de recepção como corrente investigativa útil para o estudo da comunicação sobre o trabalho, no trabalho e como trabalho. Para isso estudaremos a concepção de trabalho do materialismo histórico, as lógicas de funcionamento e implicações sociais da linguagem e o trabalho como mediação no marco teórico dos Estudos de Recepção.

Palavras-chave: Comunicação e trabalho; Linguagem; Estudos de recepção; Mediações.

Labour as a communication mediator: A theoretical reflection on the binomial communication-labour and reception studies

Abstract: This paper is located in the binomial communication-labour, seeking to reflect on the reception studies as investigation perspective useful for the study of communication about labour, at labour and as labour. For this, we will study the historical materialism concept of work, the operating logics and social implications of language and work as a mediator in the theoretical framework of Reception Studies.

Keywords: Communication and labour; Language; Reception studies; Mediations. 


\section{Introdução}

O estudo do trabalho no campo da Comunicação, desde uma perspectiva não funcionalista, é relativamente recente no Brasil. O seu estudo tem sido desenvolvido de forma pioneira pelo Centro de Pesquisa em Comunicação e Trabalho da Escola de Comunicação e Artes da Universidade de São Paulo fundado e coordenado pela Dra. Roseli Fígaro desde 2003. Não se trata do estudo da comunicação organizacional, tampouco busca compreender os usos da comunicação no trabalho para aprimorar seus efeitos. Em contraste, os estudos do centro buscam compreender como a comunicação organiza, constrói e transforma redes de sentido no mundo do trabalho que está em permanente mudança. As pesquisas também demonstram como a relação emissor-receptor constrói sentidos marcados através dos discursos que circulam no mundo do trabalho e das mudanças que ali se operam. Assim, o trabalho situa-se como uma mediação importante na construção de sentidos que circulam em toda a vida social e que reverberam na subjetividade dos indivíduos. Isto é, os sujeitos são transformados pelo mundo e incidem no mundo que os transformou. Revela-se, portanto, a aderência à percepção da relação dialética entre ser e objeto, permitindo retomar a discussão sobre os paradigmas que orientam o campo da Comunicação.

\section{Trabalho}

Os estudos do binômio comunicação-trabalho partem da oposição ao idealismo subjetivista de Jürgen Habermas - o primeiro estudioso a propor uma teoria da comunicação, a teoria da Ação Comunicativa. Para Habermas, não existe objeto sem sujeito; a relação que dá existência ao ser humano é a relação com outro sujeito. Em contrapartida, os estudos de comunicação-trabalho encontram no materialismo histórico uma explicação mais precisa para a relação ser-objeto. Marx e Engels estudam a vida social no contexto histórico e material. Isto é, concebem o homem no contexto social, redefinindo as relações entre sujeito e objeto, subjetividade e objetividade. Para os autores de A Ideologia Alemã (2007: 33), a primeira premissa de toda a existência humana é a de que "os homens têm de estar em condições de viver para poder 'fazer história'". Logo, para viver, os homens precisam, antes de tudo, de comida, bebida, moradia, vestimenta, etc. Assim, o primeiro ato histórico do homem é "a produção dos meios para a satisfação dessas necessidades, a produção da própria vida material" (MARX \& ENGELS, 2007: 33). Esse embate entre o homem e o mundo compreende-se nos estudos de comunicação-trabalho como trabalho, ao passo que emprego é o vínculo de um sujeito com uma pessoa jurídica (ou física) em troca de uma remuneração. Portanto, o trabalho, enquanto uso das faculdades físicas e intelectuais no mundo, é uma ação constituinte do ser humano. A interação da subjetividade não se dá apenas ser-ser, mas sim, ser-meio. Marx e Engels enfatizam que "a história da humanidade deve ser estudada e elaborada sempre em conexão com a história da indústria e das trocas" (MARX \& ENGELS, 2007: 34). Para eles "a história nada mais é do que o suceder-se de gerações distintas, em que cada uma delas explora os materiais, os capitais e as forças de produção a ela transmitidas pelas gerações anteriores" (MARX \& ENGELS, 2007: 40).

\section{Linguagem}

Outro elemento ontológico do homem é a linguagem. Para Marx e Engels a linguagem é constitutiva da consciência humana:

Somente agora, depois de já termos examinado quatro momentos, quatro aspectos das relações históricas originárias, descobrimos que o homem tem também 'consciência'. Mas esta também não é, desde o início, consciência 'pura'. O 'espírito' sofre, desde o início, a maldição de estar 'contaminado' pela 
matéria, que, aqui, se manifesta sob a forma de camadas de ar em movimento, de sons, em suma, sob a forma de linguagem. A linguagem é tão antiga quanto a consciência - a linguagem é a consciência real, prática, que existe para os outros homens e que, portanto, também existe para mim mesmo; e a linguagem nasce, tal como a consciência, do carecimento, da necessidade de intercâmbio com outros homens (MARX \& ENGELS, 2007: 40).

A necessidade de intercâmbio com outros homens, a partir da qual nasce a linguagem e a consciência, diz respeito à necessidade de estabelecer comunicação com os sujeitos a sua volta. Por sua vez, se entendemos que trabalho (diferentemente de emprego) é a produção dos meios para a satisfação das necessidades para a sustentação da vida, a comunicação surge da necessidade de estabelecer contato para o desenvolvimento do trabalho, ou seja, para assegurar a manutenção da existência.

Leontiev também reconhece a relação dialética entre ser e objeto. Em diálogo com Marx, o psicólogo russo assinala que ao mesmo tempo que o homem age sobre a natureza e a modifica, "ele modifica sua própria natureza também e desenvolve as faculdades que nele estão adormecidas" (LEONTIEV, 2004: 80). Entre essas faculdades, encontra-se a linguagem. Para Leontiev, a linguagem é formada no embate do homem com o mundo. Ele afirma que "a produção da linguagem como da consciência e do pensamento está diretamente misturada na origem à atividade produtiva, à comunicação material dos homens" (LEONTIEV, 2004: 81). Isto é, o desenvolvimento da linguagem não é uma questão puramente psíquica, mas também é uma questão social. Essa compreensão é compartilhada pelo psicólogo bielorrusso Lev Semenovitch Vigotsky, o qual explica em Pensamento e Linguagem que "o pensamento verbal não é uma forma de comportamento natural e inata, mas é determinado por um processo históricocultural", portanto, "a natureza do próprio desenvolvimento se transforma, do biológico para o sócio-histórico" (VIGOTSKY, 2005: 63).

Para Vigotsky, o crescimento intelectual da criança depende de seu domínio dos meios sociais do pensamento, em outros termos, o domínio da linguagem. "O desenvolvimento do pensamento é determinado pela linguagem, isto é, pelos instrumentos linguísticos do pensamento e pela experiência sociocultural da criança" (VIGOTSKY, 2005: 62). O autor não deixa dúvidas sobre a proximidade do seu pensamento com o materialismo histórico. Ele enfatiza que "uma vez admitido o caráter histórico do pensamento verbal, devemos considerá-lo sujeito a todas as premissas do materialismo histórico, que são válidas para qualquer fenômeno histórico na sociedade humana" (VIGOTSKY, 2005: 63).

Portanto, os estudos da comunicação-trabalho situam-se no paradigma teórico que compreende que o processo de hominização se dá em contato com o mundo material. Em outras palavras, no embate do ser com o meio. $O$ trabalho é compreendido como primeiro ato histórico da existência humana. A consciência se desenvolve e se organiza em interdependência com a linguagem, a qual é estudada como um elemento social. Não se trata apenas de sons foneticamente pronunciáveis ou de uma estrutura semântica com normas e regras. Os estudos da linguagem são compreendidos como "formulações em que o conhecimento é concebido, produzido e recebido em contextos históricos e culturais específicos" (BRAIT, 2006: 10). Esta é também a perspectiva do Círculo de Bakhtin.

O Círculo de Bakhtin busca compreender a linguagem em uso, e não precisamente as estruturas da língua. Bakhtin afirma: "temos em vista o discurso, ou seja, a língua em sua integridade concreta e viva e não a língua como objeto específico da Linguística" (BAKHTIN in BRAIT, 2006: 11). A nova disciplina é intitulada de Metalinguística, frisando o estudo das questões do uso concreto da 
linguagem no cotidiano, isto é, das questões extralinguísticas. Arisca-se a dizer que a metalinguística estuda a língua real, e não a língua prescrita, normatizada nos manuais de gramática.

Bakhtin (1988) assinala que as bases para uma teoria marxista da criação ideológica estão estreitamente ligadas aos problemas da filosofia da linguagem. "Um produto ideológico faz parte de uma realidade (natural ou social) como todo corpo físico, instrumento de produção ou produto de consumo; mas ao contrário destes, ele também reflete e refrata uma outra realidade, que lhe é exterior" (BAKHTIN, 1988: 31). Entende-se, portanto, que a realidade é inapreensível de forma 'pura'. Ela manifesta-se por meio dos signos. Dito de outra maneira, a realidade é semiotizada pelos sujeitos e para os sujeitos. Dessa forma, os signos funcionam como mediadores da interação do homem com o mundo.

Por outro lado, todo signo é ideológico, possui significado e está sujeito à avaliação. Para Bakhtin (1988: 32), "um signo não existe apenas como parte de uma realidade; ele também reflete e refrata uma outra", uma vez que ele pode distorcê-la, apreendê-la sob um ponto de vista específico ou ser-lhe fiel. Avaliar ou conhecer um novo signo implica em mobilizar o capital cultural adquirido, que em suma são signos ideológicos já conhecidos. Nas palavras do filósofo, "conhecer um signo consiste em aproximar o signo apreendido de outros signos já conhecidos; em outros termos, a compreensão é uma resposta a um signo por meio de signos" (BAKHTIN, 1988: 32). Por isso, o signo, afirma-se mais uma vez, é ideológico, é mutante e refrata uma nova realidade, aquela apreendida pelo sujeito.

As linhas anteriores explicam o que Bakhtin chama de dialogismo. Os discursos não se relacionam diretamente com as coisas, mas com outros discursos que lhes dão sentido. Fiorin (2009) explica que o dialogismo é o modo de funcionamento real da linguagem, seu princípio constitutivo e a forma particular da composição do discurso. "Como não existe objeto que não seja cercado, envolto, embebido em discursos, todo discurso dialoga com outros discursos, toda palavra é cercada de outras palavras" (BAKHTIN in FIORIN, 2009: 167).

Esta perspectiva de estudos da linguagem é particularmente elucidativa para os estudos do binômio Comunicação e Trabalho, os quais pesquisam, desde a abordagem ergonômica, os discursos dos trabalhadores, em ambientes de trabalho, sobre questões de trabalho.

Para tornar metodologicamente manejável a relação linguagem/trabalho, Lacoste (1995) a sistematizou em três modalidades: linguagem sobre trabalho, linguagem no trabalho e linguagem como trabalho. Nouroudine (2002) apresenta estas três modalidades como formas de coletar e analisar os discursos.

A linguagem como trabalho refere-se à linguagem como ferramenta técnica para o desenvolvimento do trabalho, isto é, a linguagem como atividade de trabalho. Por exemplo, o professor que mobiliza o discurso pedagógico como ferramenta para exercer seu trabalho, educar. A linguagem no trabalho é a linguagem circundante. A atividade comunicativa que participa indiretamente em ambientes de trabalho. Esta linguagem é constitutiva de situações nas quais acontece o trabalho. São as conversas de corredor, o cafezinho, o bate-papo após a reunião. Elas nutrem uma dimensão social do trabalhador. A linguagem sobre trabalho é a linguagem que interpreta, são as narrativas sobre o trabalho; são os desabafos sobre o trabalho com os familiares em casa, as histórias do trabalho com as crianças, etc. (NOUROUDINE, 2002). 
$\mathrm{Na}$ análise das práticas linguagueiras, Faïta (2002) recomenda a estratégia da confrontação cruzada, que primeiramente consiste em filmar o sujeito no trabalho. Em segunda instância, a filmagem é assistida pelo mesmo trabalhador, para que expresse seus comentários. O último passo consiste em filmar o trabalhador comentando a filmagem da atividade de trabalho. Os seus discursos são os dados primários da análise. Na estratégia de Faïta, poderá ser distinguida nitidamente a linguagem no trabalho da linguagem sobre o trabalho. Contudo, é interessante notar que, em situação de entrevista, o sujeito pesquisado poderá enunciar tanto narrativas sobre o trabalho, como reproduzir discursos no trabalho e como trabalho.

Os discursos coletados poderão ser analisados mediante a Análise de Discurso de linha francesa. A AD é um método analítico que dialoga com a concepção ontológica que concebe a linguagem como elemento constitutivo do ser humano. Ela não se limita ao estudo puramente linguístico, mas leva em conta aspectos externos: o contexto imediato da situação de comunicação, ou seja, a compreensão dos elementos históricos, sociais, culturais, ideológicos que cercam a produção de discurso e nele se refletem. Além disso, Brandão explica que na Análise de Discurso da linha francesa "considera-se o espaço que esse discurso ocupa em relação a outros discursos produzidos e que circulam na comunidade" (BRANDÃO, 2012: 21). A Análise de Discurso se revela uma técnica de análise própria para estudar as práticas linguagueiras no mundo do trabalho, uma vez que nos seus pressupostos teóricos encontra-se a noção de que a linguagem é construída e reconstruída no uso, isto é, no embate com o mundo social.

Estudando sobre a relevância dos estudos de linguagem para o binômio comunicação-trabalho, Fígaro afirma que:

(...) o que interessa à abordagem de comunicação e trabalho é a compreensão de que a realidade está na linguagem por meio do percurso sócio-histórico e cultural da experiência humana. Ou seja, a realidade é cognoscível e como tal torna-se realidade fabricada pela capacidade humana de atividade. Diferentemente do objeto da lingüística e da pragmática, para a Comunicação a linguagem interessa pelo seu potencial de dar a conhecer como se estabelecem as redes de relações, quais e como circulam os valores e os pontos de vista nos quais se fundamenta a cultura na sociedade contemporânea. (FIGARO, 2009: 30)

A construção, circulação e ressignificação de valores, pontos de vistas e sentidos são objetos de pesquisa dos Estudos de Recepção, os quais nascem dos Estudos Culturais, que é o paradigma teórico que propõe compreender como cultura todo rastro da interação do homem no mundo. Os Estudos de Culturais se fundam na relação dialógica entre ser e meio e vão ao encontro das concepções dos estudos de linguagem e trabalho apresentados anteriormente.

\section{Estudos Culturais}

$\mathrm{Na}$ Inglaterra de meados do século XX o debate sobre cultura dá-se numa sociedade capitalista, industrial. Nesse contexto, Raymond Williams (1921-1988), uma das figuras centrais da fundação dos Estudos Culturais, percebia que a concentração no debate da cultura apontava o que foi denominado de 'era da cultura', em virtude do predomínio dos meios de comunicação de massa e do deslocamento do conflito político e econômico para o cultural. Ele sugere pensar as mudanças culturais atreladas e intimamente ligadas às mudanças econômicas, tecnológicas, comunicacionais e de consumo (CEVASCO, 2003).

Assim, os Estudos Culturais emergem em meados da década de 1950 para pensar a cultura sob um prisma diferente, descentrando o foco na noção de 
cultura como apenas cultura erudita para formas várias de culturas (no plural) para uma concepção mais ampla. As suas questões caraterísticas encontram-se em três livros de ruptura com o cânone: As utilizações da cultura ([1957] 1973), de Richard Hoggart, Cultura e Sociedade ([1958] 2011a), de Raymond Williams, e A formação da classe operária inglesa ([1963] 2011), de Edward Palmer Thompson. Hoggart estudou as tradições culturais da classe trabalhadora urbana e o impacto da cultura de massas sobre seus hábitos e costumes. Williams defendeu a unidade entre cultura e sociedade e propôs uma cultura em comum, alegando igualdade entre a cultura popular e a cultura erudita. Thompson reconstruiu uma parte da história da classe trabalhadora inglesa, reconhecendo assim as culturas populares e suas resistências (CEVASCO, 2003).

Essas publicações são consideradas seminais e de formação; seus autores são chamados de pais fundantes deste novo espaço de estudo e prática que, em ruptura com o cânone, chamou-se de Estudos Culturais. Assim, os Estudos Culturais são considerados por Mattelart e Neveu um novo paradigma teórico que busca entender a cultura visando particularmente à relação entre a vida cotidiana de grupos e a condição hegemônica:

Pode-se qualificar, portanto, a emergência do Cultural Studies como a de um paradigma, de um questionamento teórico coerente. Trata-se de se considerar a cultura em seu sentido amplo, antropológico, de passar de uma reflexão centrada sobre o vínculo da cultura-nação para uma abordagem da cultura dos grupos sociais. [...] a questão central é compreender em que a cultura de um grupo, e inicialmente das classes populares, funciona como contestação da ordem social ou, contrariamente, como modo de adesão às relações de poder. (MATTELART; NEVEU, 2004: 13-14)

Mais do que uma ideia conceitualmente clara, a definição de cultura está em permanente construção, devido à sua complexidade e riqueza. Os Estudos Culturais seguem uma linha de pensamento democrático que:

Define cultura ao mesmo tempo como os sentidos e valores que nascem entre as classes e grupos sociais diferentes, com base nas suas relações históricas, pelas quais eles lidam com suas condições de existência e respondem a estas; e também como as tradições e práticas vividas através das quais esses entendimentos são 'expressos' e nos quais estão incorporados (HALL, 2003: 142).

Apontando para a gênese do debate, Williams afirma que "uma cultura não é apenas um corpo de trabalho intelectual e imaginativo; ela é também e essencialmente todo um modo de vida." (WILLIAMS, 2011a: 349). Por sua vez, Hall conclui que o paradigma dominante nos Estudos Culturais entende a "cultura como algo que entrelaça todas as práticas sociais; e essas práticas, por sua vez, como uma forma comum de atividade humana: como práxis sensual humana, como atividade através da qual homens e mulheres fazem a história." (HALL, 2003: 141-142).

Assim, conclui-se que a cultura é o resultado da interação do homem com a sociedade. Portanto, todo sujeito, sem importar a classe e a escolaridade, produz cultura e consome cultura na mesma medida em que interage com o mundo. Com essa premissa teórica, Williams propõe um estudo da comunicação humana e não só midiática. Propõe uma integração entre comunicação natural e a tecnológica e o estudo social e cultural da comunicação. Williams afirma que "é verdade que os meios de comunicação, das formas físicas mais simples da linguagem às formas mais avançadas da tecnologia da comunicação, são sempre social e materialmente produzidos e, obviamente, reproduzidos" (WILLIAMS, 2011b: 69). 
Apreendemos, portanto, que os estudos de comunicação-trabalho podem pesquisar não apenas os discursos na comunicação midiática, mas também aqueles enunciados na comunicação oral, pelo meio de comunicação mais democrático de todos, o aparelho fonador. Também, compreendemos que o estudo do trabalho e da linguagem como elementos constituintes do homem na sua interação com o mundo, é o estudo da cultura. Estudar comunicação-trabalho é estudar a cultura.

\section{Estudos de Recepção}

Do paradigma dos Estudos Culturais emergem os Estudos de Recepção. Eles são, em primeira instância, outra perspectiva de investigação do campo da comunicação e não uma área de pesquisa de um dos componentes do processo comunicacional.

Para os estudos de recepção latino-americanos a cultura é um importante local de onde se pode estudar a comunicação. No estudo do processo comunicacional, os estudos de recepção encontram no macrossocial elementos culturais, sociais, económicos, políticos, religiosos incidentes na recepção das mensagens, interpretação e ressignificação. Esses elementos são chamados de mediações.

O filósofo Jesus Martín-Barbero, na introdução da primeira edição do seu clássico Dos Meios às Mediações, publicado pela Editorial Gustavo Gili em Barcelona, explica que até então a pesquisa em comunicação na América Latina se dedicou a indagar "cómo nos manipula ese discurso que a través de los medios masivos nos hace soportable la impostura, cómo la ideología penetra los mensajes imponiéndole desde ahí a la comunicación la lógica de la dominación". Contudo, os processos políticos e sociais da época, a saber, regimes autoritários em quase toda Améria do Sul, cercados de lutas, resistências, migrações abriram novas brechas investigativas. Para Martín-Barbero (1987: 10), esses conflitos:

(...) nos enfrentaron a la verdad cultural de estos países: al mestizaje que no es sólo aquel hecho racial del que venimos, sino la trama actual de modernidad y discontinuidades culturales, de formaciones sociales y estructuras del sentimiento, de memorias e imaginarios que revuelven lo indígena con lo rural, lo rural con lo urbano, el folklore con lo popular y lo popular con lo masivo. Fue así como la comunicación senos tornó cuestión de mediaciones más que de medios, cuestión de cultura y, por tanto, no sólo de conocimiento sino de reconocimiento (MARTíN-BARBERO, 1987: 9).

Martín-Barbero propõe, portanto, a superação de uma visão objetivista dos meios (a indústria cultural, a tecnologia e seus produtos) e redireciona a pesquisa para estudar a inserção cultural do receptor. Estudando minuciosamente essa proposta, o pesquisador brasileiro José Luiz Braga explica que:

Em perspectiva epistemológica, trata-se do relacionamento do ser humano com a realidade que o circunda, que inclui o mundo natural e a sociedade. $A$ ideia de mediação corresponde à percepção de que não temos um conhecimento direto dessa realidade - nosso relacionamento com o 'real' é sempre intermediado por um 'estar na realidade' em modo situacionado, por um ponto de vista - que é social, cultural, psicológico. O ser humano vê o mundo pelas lentes de sua inserção histórico-cultural (JOSÉ LUIZ BRAGA, 2012: 32).

Desde a primeira publicação do livro até o presente, Martín-Barbero tem revisitado suas propostas teóricas buscando compreender as relações entre comunicação, cultura e poder. Assim, o pesquisador primeiramente introduziu o estudo das mediações culturais da comunicação e, em entrevista para a revista 
Matrizes, em 2009, apresentou a transição para as mediações comunicativas da cultura.

No mapa das mediações culturais da comunicação aparecem dois eixos: o primeiro nas lógicas de produção e nas competências de recepção; o outro, nas matrizes culturais e nos formatos industriais. Estas mediações se referem a elementos socioculturais que agem na formulação de sentidos. Já as mediações comunicativas da cultura passam a ser notadas pelo pesquisador a partir de meados dos anos 1990 com a massificação do computador, internet e daquilo que veio com eles. Na entrevista, o autor explica: "inverto meu primeiro mapa e proponho as 'mediações comunicativas da cultura', que são: a 'tecnicidade'; a 'institucionalidade' crescente dos meios como instituições sociais e não apenas aparatos, instituições de peso econômico, político, cultural" (MARTíN-BARBERO, 2009: 151). Essa guinada teórica enfatiza o estudo da centralidade das TIC's na vida social contemporânea. Coloca a comunicação como "movimiento que atraviesa y disloca a la cultura. Pues el lugar de la cultura en la sociedad cambia cuando la mediación tecnológica de la comunicación deja de ser meramente instrumental para convertirse en estructural" (MARTíN-BARBERO, 2002: 225).

O trabalho é tido como uma importante mediação que atinge a construção de sentidos de forma ampla dado a seu caráter de elemento constitutivo do ser humano. Ele perpassa as mediações do terceiro mapa de Jesus Martín-Barbero institucionalidade, ritualidade, tecnicidade e sociabilidades. Para Fígaro, estudar o binômio comunicação-trabalho permite:

(...) entender a partir de que valores as pessoas fazem suas escolhas; como se constituem os coletivos de trabalho que estão fora do enquadramento do organograma da empresa; como se constituem as redes de ajuda e solidariedade na resolução de problemas e tarefas. É, ainda, compreender como o mundo do trabalho transborda de seu meio e abarca outros espaços sociais, tais como a casa, o bairro, a mídia, etc. (FíGARO, 2009: 38)

Incorporando a expressão 'uso de si' de Yves Schwartz (2006), Fígaro explica que "trabalhar é gerir o uso de si por si mesmo e de si pelo outro, estabelecendo redes de comunicação [...]. Se trabalhar é sempre trabalhar com o outro e comunicar é relação, troca, reelaboração, podemos afirmar que ambos, comunicação e trabalho, atuam na construção dos conjuntos de valores que se renovam ou se cristalizam a cada escolha feita, a cada decisão do uso de si por si mesmo" (FÍGARO, 2009: 38).

\section{Considerações}

Os estudos de recepção como marco teórico nas pesquisas sobre a comunicação no mundo do trabalho permitem destacar a relação dialética entre micro e macrossocial. Somado ao materialismo histórico, que compreende o trabalho de forma ampla, esta atividade humana se torna uma importante mediação, influente na recepção, reelaboração, produção e troca de ideias, valores, percepções da realidade, cuja influência extrapola os ambientes laborais e desemboca no cotidiano familiar, na relações sociais diversas e nas identidades. Diante disso, compreende-se que o estudo da intersecção comunicação e trabalho colabora na melhor compreensão das relações de comunicação, o processo de comunicação (construção e compartilhamento de sentidos) e os sujeitos da comunicação.

Fígaro exorta: "a dimensão de comunicação e trabalho como atividade humana singular, resultada de um processo dinâmico na ontogênese e na filogênese da história, requer que nos coloquemos diante da realidade a conhecer de uma maneira mais aberta e menos pretensiosa" (FíGARO, 2009: 39). 
Propõe-se, portanto, estudar o trabalho como mediação incidente no processo de recepção. Trata-se de uma mediação líquida, que se espalha nas diversas faces da vida social. Vemos o trabalho como uma mediação social, institucional, técnica e ritualística. Como ambiente de socialização, lugar de encontro e interação, o trabalho medeia em forma de sociabilidade. Por outro lado, o trabalho medeia por regimes de institucionalidade enquanto instituição normalizadora de procedimentos e padrões e entidade que institui a cartilha do parâmetro e da norma. As rotinas de produção, o tempo do descanso e do lazer, a gramática que regula a interação entre espaços e tempos são manifestações do trabalho como mediação de ritualidade. Por fim, o trabalho como um saber fazer, como a atuação de operadores perceptivos e destrezas discursivas trazem a tona a mediação da tecnicidade.

Esta proposta é colocada para apreciação e análise. Pesquisas empíricas poderão revelar a pertinência dos conceitos articulados e elucidar o estudo do binômio comunicação-trabalho.

\section{Referências}

BAKHTIN, M. (VOLOSHINOV) Marxismo e filosofia da linguagem. São Paulo: Hucitec, 1988.

BRAGA, J. L. Circuitos versus campos sociais. In: MATTOS, M. A.; JANOTTI, J. J.; JACKS, N. (Orgs.). Mediação e Midiatização. Salvador: EDUFBA, 2012: 31-52.

BRANDÃO, H. Enunciação e construção do sentido. In: FíGARO, R. A. (org.) Comunicação e Análise do Discurso. São Paulo: Contexto, 2012.

BRAIT, B. (org.). Bakhtin: Outros conceitos-chave. São Paulo: Contexto, 2006.

CEVASCO, M. E. Dez lições sobre estudos culturais. São Paulo: Boitempo Editorial, 2003.

FAÏTA, D. A análise de práticas linguageiras e situações de trabalho: uma renovação metodológica imposta pelo objeto. In: SOUZA E SILVA, M. C P.; FAÏTA, D. (orgs.) Linguagem e trabalho. Construção de objetos de análise no Brasil e na França. São Paulo: Cortez, 2002.

FíGARO, R. A. Comunicação e Trabalho: binômio teórico produtivo para as pesquisas de recepção. Mediaciones Sociales. Revista de Ciencias Sociales y de la Comunicación, no 4, primer semestre de 2009: 23-49.

FIORIN, J. L. Interdiscursividade e Intertextualidade. In: BRAIT, B. (org.). Bakhtin. Outros conceitos-chave. São Paulo: Contexto, 2006.

HALL, S. Da diáspora: identidades e mediações culturais. Belo Horizonte: Editora UFMG, 2003.

LEONTIEV, A. O desenvolvimento do psiquismo. São Paulo: Centauro, 2004

MARTÍN-BARBERO, J. De los medios a las mediaciones: comunicación, cultura e hegemonía. Barcelona: Editorial Gustavo Gali, 1987.

Oficio de Cartógrafo: travesías latinoamericanas de la comunicación en la cultura. Santiago de Chile: Fondo de Cultura Económica, 2002.

Uma aventura epistemológica. Entrevistador: Maria Immacolata

Vassalo de Lopes. Matrizes, São Paulo, v. 2, n. 2, p. 143-162, 2009. 
MARX, K., ENGELS, F. A ideologia alemã. São Paulo; Boitempo, 2007.

MATTELART, A.; NEVEU, E. Introdução aos Estudos Culturais. São Paulo: Parábola Editorial, 2004.

NOUROUDINE, A. A linguagem: dispositivo revelador da complexidade do trabalho. In: SOUZA E SILVA, M. C. P., FAÏTA, D. (orgs.) Linguagem e trabalho. Construção de objetos de análise no Brasil e na França. São Paulo: Cortez, 2002.

SCHWARTZ, Y. Entrevista Yves Schwartz. Revista Trabalho, Educação, Saúde. Fiocruz, v. 4 n. 2, p. 457-465, 2006.

WILLIAMS, R. Cultura e Sociedade: de Coleridge a Orwell. Petrópolis, RJ: Vozes, 2011a.

Cultura e materialismo. São Paulo: Editora Unesp, 2011b.

VYGOTSKI, L. S. Pensamento e linguagem. 3.ed. São Paulo: Martins Fontes, 2005. 